\title{
ПЕРВАЯ ВСЕСОЮЗНАЯ КОНФЕРЕНЦИЯ ПО СТАТИСТИЧЕСКОИ РАДИОФИЗИКЕ
}

С 13 по 18 октября 1958 г. в Горьком проходила 1 Всесоюзная конференция по статистической радиофизике Министерства высшего образовання и AH CCСP. По поручению АН СССР, МBO СССР и ВНТОР и $Э$ нм. А. С. Попова конференция была организована и проведена Научно-исследовательским радиофизнческим институтом при Горьковском государственном университете им. Н. И. Лобачевского (НИРФИ). В ее работе принял участие ряд крупных специалистов в области статистической радиофизнки (С. М. Рытов, М. Л. Левин, И. Л. Берштейн и др.), а также представители большинства ведущих научно-исследовательских радиофизических II раднотехнических организаций, высших учебных заведений различных городов Советского Союза.

Работа конференции проводилась по трем секциям.

Пленарное заседание 13 октября откры.т проф. С. М. Рытов (ФИАН Москва). В своем вступительном слове он охарактеризовал статистическую радиофизнку, кақ неотъемлемую часть соврөменной раднофнзикн, $K$ раднофнзике обычно прниято относить радноастрономию, радиосиектроскопио, электронику и электродинамику СВЧ, электромагнитные свойства вещества в радиодиапазоне, электродинамику плазмы и т. д. Если вникнуть в содержание этाх областей науки, то можно выделить два направления нсследования нанболес тесно связанных с раднотехникой: экспериментальное и теоретнческое изучение всевозможных физических явлений, существенных для радиосвязи (генерацил, распространенге и прием радноволн), т. е. физика для радиотехннки; и изучение методами современной радиотехники тех или иных фпзических объектов, т. е. радиотехника д.я физики.

Такое понимание радиофизики позволяет очертить круг интересов статистнческой радиофизики. Последняя зангмается изучением случайных (в том числе флюктуационных) явлений, с которыми приходится сталкиваться в каждой из названных выше областей и которые в наше время, благодаря заІросам науки и техники, приобрели решающее значение. Будучи столь широкой по своему охвату, статистнческая радиофизика едина свонми физическими (термодинамнка и статнстическая физика) и математическими (теория вероятностей - с.тучайных величин II теория случайных процессов) методами. Ограннчиваясь тем направлением радиофизики, которое охарактеризовано выше как физика для радиотехники, нетрудно определить содержание статистіческой радиофизики. В области генерации радиоволн статистическая радиофпзика занимается исследованием ф.љюкуаинй в автоколебательных системах и связанных с ними вопросов о стабниыности частоты и о тонностн еe определения.

Необходимо указать, что наша отечественная радиофизика идет здесь в первых рядах мировой науки по давней научной традищин, берущей свое начало еше от $\Pi$. И. Мандельштама А. А. Мидронова и интенсивно развивавшейся особенно в Горьком благо. даря работам Г. С. Горелика, И. Л.Берпштейна и В. С. Троицкого.

Доктадчик подчеркнул актуальность статистических задач кваптовой радистехники, вопросов чувствнтельости 
квантовых усилителей и стабильности квантовых генераторов, так как от фнзических результатов в этой области во многом зависит техническое решение ряда важных практических и теоретических задач.

В области распространения радиоволн статистическая радиофизика изучает влияние случайных неоднородностей среды. Сюда же относится и вопрос о влиянии на распространение случайных неоднородностей границ.

И, наконец, при приеме радиосигналов крайне существенна статистика шумов в приемных и измерительных устройствах, трансформация внешних и внутренних шумов при разного рода преобразованиях сигналов в аппаратуре, вопросы выявления сигналов и помехоустойчивости.

Что касается применений статистической радиофизики в том направленин, которое выше было охарактеризовано как радио для физики, то они поистине неисчерпаемы и охватывают применение радио в астрономии, спектроскопии, ускорении заряженных частиц, разогреве плазмы при управляемых термоядерных реакциях, оптике, акустике и т. д.

Во многих случаях как радиотехников, так и радиофизиков интересует область статистической радиофизики, в которой тесно смыкаются и радиотехника для физики и физика для радиотехники. Эта область - физическая природа исследуемых флюктуаций и шумов. Для радиотехники, как таковой, важно изучение шумов в диэлектриках, полупроводниках и контактах, магнитных шумов, шумов в электронных потоках, в электрическом разряде, в плазме, эффекта мерцания, теплозых шумов как в классической, так ін в квантовой области и т. д. С. М. Рытов полагает, что в настоящее время мы находимся на достаточно удовлетворительном уровне лишь в области теории тепловых шумов, а в целом состояние этого чрезвычайно актуального вопроса далеко не блестяще, число опубликованных работ, также как и число докладов на эту тему на данной конференции явно недостаточно. На этом же заседании выступил член-корреспондент АН СССР В. И. Сифоров с докладом: «Қ теории каналов радиосвязи со случайно изменяющимися параметрамн». Присутствующие с большим интересом ознакомились с новыми результатами в смежной области статистической теорин связи (теория информации)

Затем с обзорным докладом «Флюктуационные явления в автоколебательных системах», выступнл И. Л. Берштейн (НИРФИ, Горький)

Eше в середине $30-x$ годов по препложению и под руководством А. А. Андронова И. Л. Берштейном был проведен анализ и расчет процессов в обычном ламповом генераторе $c$ учетом флюктуационных воздействий дробового эффекта в лампе и теплового эфіфекта в контуре. Анализ показал, что ф.люктуационыые толчки вызывают хаотические отклонения амплитуды и фазы колебаний. Отклонения амплитуды в силу динамических свойств системы затухают со временем. Между тем, любое отклонение фазы допускается дннамикой системы, а потому наблюдается накопление случайных отклонений, что, в свою очередь, приводит к диффузнонной зависимости среднего квагтрата случайного набега фазы от времени.

Уровень флюктуации фазы определяет естественную ширину линии генератора или, иначе говоря. по порядку величины принципиальный предел относительной стабильности частоты генератора. Для обычных генераторов естественная размытость спектра колебаний в относительных единицах составляет по порядку величины $10^{-11}-10^{-15}$. Однако на опыте наблюдается ширина линии на 6-7 порядков больше естественной, обусловленная наличием в реальных устройствах более грубых возмущающих факторов. $\mathrm{K}$ ним следует отнести: фликкер-эффект в лампе, непостоянство напряжений питания и температуры, вибрацию электродов и т. д. По предложению Г. С. Горелика такого рода факторы полудили название технических причин, а обусловленная ими ширина линии генератора - технической.

В $40-x$ годах в связи с разработкой чувствительных приемников сантиметрового диапазона вопрос о флюктуациях в генераторе приобретает практическую актуальность. В 1949 г. в ГИФТИ (Горький) было проведено экспериментальное исследование флюктуаций колебаний обычного лампового генератора. Анализ спектральной плотности флюктуаций частоты тенератора в функции частоты показал, что при частотах меньших $10 \mathrm{\kappa a \zeta} \mathrm{наблюдается}$ значительный рост, объясняемый воздействием технических причин. Спектральное исследование флюктуаций позволило наглядно разобрать влияние технических и өстественных причин на флюктуации в автоколебательных системах. За последние годы появилось большое количество работ, посвященных флюктуациям в генераторах.

Г. С. Гореликом был дан простой и иаглядный вывод закона фазовых флюктуацнй и проведена четкая классификация источников возмущений. Блакьер (Франция) рассмотрел флюктуации фазы кварцевого генератора, подчеркнув свлзь этого вопроса c npeдельной точностью, достижимой $\mathrm{c}$ помощью кварцевых часов. С. М. Рытов развил метод расчета флюктуаций $c$ использованием разложения решения уравнений системы в ряд по малому параметру. Им и его сотрудниками рассмотрен ряд частных схем генераторов.

Интересный анализ связи статистических закономерностей флюктуаций фазы, частоты со спектром колебания был проведен Д. Мнддлтоном (США), В. С. Тро- 
ицким и А. Н. Малаховым (СССР). А. Н. Малаховым рассмотрены $R C$-генераторы, М. Е. Жаботинский и П. Е. Зильберман (Москва) проанализирова.ли флюктуации в кварцевых генераторах. В. С. Троицким проведен анализ ф.юю:туаций колебания молекулярного гене. ратора: астественная ширина линни которого, согласно расчетам В. С. Троникого, оказалась равной $10^{-4} 2 \psi$. Порядок этой величины принципиально может быть реализован и у обычного генера. тора, но преимуществом молеку.лярного генератора является значите.тьно мень шее влияние технических факторов.

Среди экспериментальнь:х работ с.ледует отметить измерение В. C. Троицким и его сотрудниками ф.люктуащи клистронных генераторов, а также многочисленные эксперимента.тьные работы B CIUA.

В заключение своето доклада И. Л. Берштейн подчеркивает актуальность исследования флюктуаций в различных генераторах, имеющих практическое применение, а также необходимость широкого теоретического и экспериментального анализа технических уходов частоты.

Последним на пленарном заседанин был заслушан доклад C. M. Рытова: «К теории флюктуаций в сильно нелинейных автоколебательных системах».

В докладе рассмотрены автоколеба. тельные системы, допускающия кусочнолинейную аппроксимацию нелинейных характеристик. Случайные силы предполагаются малыми и коротко коррелированными. Для простоты теория развита для частного случая системы с одной степенью свободы. Фазовое пространство рассматриваемой системы - плоскость, разделенная на две полуплоскости бесконечной прямой. Методом точечных преобразований исследуются малые флюктуации в окрестности устойчивого предельного цикла. Получены статистические характеристики, и, в гастности, коэффииент диффузии «фазы». В пренебрежении флюктуациями «амплитуды» получен спектр автоколебаний. Показано, что ширина линий на уровне половинной пнтенсивности про порциональна квадрату номера гармонн. ки, а их ннтегратьная интенснвность $T$ : же, что и в отсутствни флюктуаций.

Рассмотрен прнмер iампового генера тора с $Z$-характеристикой, контуром в аноде и индуктивной обратной связью.

14-17 октября проходи.та работа секций.

Секция "Флюктуации в автоколебательных, радиоизлерительньх и усили тельмых системаху (руководители: И. Л. Берштей̈, С. М. Рытов).

В связи с интенсивным исследованием B течение последних двух лет парамет рических систем в диапазоне СВЧ и их использованием в качестве усилителей, генераторов и смеситалей особый инте pec, по нашему мнению, приобретают работы, в которых, пусть даже косвенно, рассматриваются ф.тюктуаци парамет- ров в линейных и нелинейных системах.

Қ их числу можно отнести ряд докладов. доложенных на секции.

छ докладе А. Н. Малахова (Горький, НИРФИ) «Ширнна спектральной линин генераторов и ф.люктуации параметров» рассмотрена автоколебательная система, описываемая дифференциальным уравнением :-ого порялка. Показано, что уширение линии генератора порождает. ся медленными (по сравнению с периодом колебаний, и быстрыми флюктуациями параметров. спектр которых группирует:я вблизи частот кратных частоте автоколебания.

В докладе Ю. М. Романовского, Р. Л. Стратонович (Москза, МГУ) «Параметрическое воздействне случайной силы на линейные и ндлинейные колебательнеје системы анәлогичная задача решается методом укороченных уравнений для уравнения второго порядка. Пля линейных систем найдены условия параметрического возбуждения при налични широкого и узкого. по сравнению с шириной полосє́ системы. спектра флюктуаций. Опреде.тены границы области главного параметрического резонанса при одновременном параметрическом воздействии гармонической си.ты и широкополосного шума. В нелинейном случае найдены законы распределения вероятностей для амплитуды и фазы.

Большое число докладов было посвящено исследованию медленных флюктуаций.

В докладе В. С. Троицкого (Горький, НИРФИ) «Спектральная ширина линии ламповых гөнераторов и фликкер-шум» излагается метод расчета влияния медленных флюктуаций на частоту и амплитуду колебаний автогенератора. Показано, что фликкер-шум лампы может влиять на флюктуации амплитуды џ частоты колебаний благодаря чему контур линни приобретает допп.теровскую форму, а его ширнна на несколько порядков превышает естественную ширину ภиния.

Ю. А. Драгиным (Горький, НИРФИ) в докладе «Исследование технических уходов частоты ламповых генераторов» изложена методика и приведены резҰ.тьтаты измереннй с генераторами в диапазоне частот 20-200 мегц. Эксперпменгально показано, что спектральная плотность частоты меняется как $1 / f$. Предложена схема генератора, обеспечивающая за счет нового типа связи лампы с қонтуром, большую стабнльность частоты, чем обычные схемы.

А. И. Чнкин (Горький, НИРФИ) в докладе «Фликкер-шум современных электронных ламп» привел результаты Іззерения спектров низкочастотных шумов радиоламп стандартных металлических и пальчиковых серий, а также радноламп с вольфрамовым катодом. Показано, что радиолампы последних выпусков обладают значительно менышим уровнем фликкер-гиумов. 
Докла д М. Е. Жаботинского и П. Е. Зильбермана (Москва, ИРЭАН) «O флюктуациях в кварцевых генераторах» был посвяццен анализу трех конкретных схем с учетом влияния дробовых и тепловых шумов. Полученные докладчиками результаты показывают, что естественная ширина линии такого генератора примерно на два порядка меньше, чем у обычного.

Серия докладов была посвящена ис: следованию флюктуаций в отражательном клистроне.

В докладе С. А. Ахманова и Г. Ф. Антонова (Москва, МГУ) «Флюктуацин в генераторе СВЧ-радиоимпульсов на отражательном клистроне» рассмотрены воздействия флюктуаций, которые проявляются в флюктуациях времени установления стационарной амплитуды нI фазы, в флюктуациях средней частоты и амплитуды высокочастотного заполнения радиоимпульса, а также в флюктуациях амплитуды и фазы в течение радионмпульса. Приводятся результаты теоретического и экспериментального исследования.

В докладе С. А. Ахманова «Медленные флюктуации частоты и амплитуды в отражательном клистроне» приводится методика и результаты эксперимен тального исследования спектральных плотностей флюктуаций частоты и амплитуды в отражательном клистроне 3-сантиметрового диапазона в диапазоне $1002 u_{\xi}-5$ кәц. Показано, что спектральная плотность флюктуаций частоты клистрона при питании от аккумуляторов по всем электродам меняется в указанном диапазоне как $1 / f$, а дисперсия фазы за время $10^{-3}-10^{-4}$ сек. определяется в основном медленными флюктуациями.

В пооладе Е. Н. Базарова и М. Е. Жаботинского (Москва), ИРЭАН) «Флюктуации в отражательном клистроне» теоретически рассмотрены флюктуацин в режиме синхронизации при резонансе второго рода и синхронизации на обертоне. Исследованы флюктуацни в автоколебательном рехиме при произвольном угле пролета.

В. Н. Никоновым (ГГУ, Горькнй) в докладе «Об исследованш флюктуациї колебаний клистронного генератора» рассмотрена случайная модуляция колебаний клистрона по амплитуде іп частоте, обусловленная наличнем слугайных процессов, связанных с электронным потоком. Показано, что интенсивность флюктуаций зависит от номера области генерации электронной расстройки и амплитуды колебаний. Вследствие низохронности генератора за счет флюктуаций амплитуды колебаний возникают дополннтельные флюктуации частоты. Экспериментально измеренные Флюктуации параметров колебанил и, в частности, полученное значение ширнны литин $\Delta f \sim 1$ ал дают хоропreе coв- падение $\mathcal{C}$ теорней, впервые развитой И. Л. Берштейном.

Доклады Г. П. Апушкинского (Леиинград) «Спектральные особенности ЛБВ и газоразрядной шумовой трубки», В. Б. Бердавцева (Моск. обл.) «О корреляцин флюктуации одномерного многоскоростного электронного потока в пространстве дрейфа», А. А. Николаева (Моск. обл.) «К теории колебаний и шпумов в многоскоростных электронных потоках» содержалі результаты исследования поведения шумов в электронных потоках.

Статистической электродинамике были посвлщены два доклада. В докладе В. И. Беспалова (Горький, ННРФИ) «Некоторые вопросы распространения волн в случайно неоднородных линиях передачи» рассматриваются дискретные и непрерывные случайные неоднородности. Найдены условия, при которых средний по ансамблю квадрат модуля коэффициента отражения совпадает со средним значением квадрата коэффициента отражения в диапазоне частот Рассмотрена корреляция коэффициентов отражения, обусловленная неоднородностями, при распространении волн различной частоты.

В докладе В. И. Таланова и Н. М. Шероновой (ГГУ), Горький) «О влияния случайных ошибок в распределении источников на диаграммы направленности антенн бегущей волны» показано, что как в случае непрерывного, так и в случае дискретного распределения излучающих элементов случайные отклонения фазовой скорости волны на антенне накладывают предел на максимально возможный коэффициент направленного действия антенны при увеличении ее длины. Для второго случая найдены функции корреляцин токов в излучателях при учете их вза. нмного влияния через поле основной волны в линии, а также выражение для средней диаграммы направленности.

Отдельным вопросам статнстической радиофизики были посвящены доклады: И. Г. Акопян (Москва, МГУ) «Влияние флюктуационных помех на синхронизацию автогенератора». Докладчик проявил большую орнгинальность в осуществлении интересного экспериментального исследования. М. З. Клюмель - «Исследование нестабильности частоты, вносимой умножителями цастоты и спектра выхолиого колебания»; Р. Л. Стратононич, П. С. Ланда (Москва, МГУ) «Воздействне шумов на генератор $\mathrm{c}$ жестким возбуждением»; Б. Б. Буховцев, А. Е. Орданович. В. И. Шмальгаузен - «Некоторые методы экспериментального определекия статистических характеристик случайных сигналов» Ю. Е. Дьяков (Москва) - «Фазовое детектирование в прнсутствии шума»; А. Н. Мапахов, А. И. Чикин (Горький, НИРФИ) - «Флюктуации коэффнциентов усилспия полупроводниковнх усплителей». 
Серьезныс позражсния со стороны участников конфсрснции встретилн отдельные положения доклада В.Ф. Мге ладзе и В. Ф. Нестерук (Тенпиград ЛКИ) - «О пекоторых методах обна ружения и измерения слабых сигналов»

Большой интерес вызвал доклад P. ग. Стратоновнч - «Оптнма.тьные нелинейные прнемиые системы, осуществляющие выделение полезного сигта та из шума», содержание которого тесно смыкается с теорией информации. и доклад K. А. Горониной и А. А. Грачева (Горький, НИРФІ) «Ф.ћюктуании при перемагничивании ферромагнетиков». Докладчиками расеиитана спектральная плотность шумов и остаточных флюктуирующих четньх гаруоник. полвляюшихся при периодическом перемагничивании ферромагнетиков. Работа позво.7яет оценить предельную чувствительность магнитных усилитслей и 301 дов.

Относительно небольшое чнсло докладов касалось физики пуумов.

В доктаде Ф. Г. Басс и М. И. Каганова (Харьков, ИРЭУАН) «Корреляцाонные соотношения для случайных электронных токов и полей при низких температурах» рассмотрено влиянне длины свободного пробега электронов на корреляционные соотношения между компонентами случайных токов и полей в металле. Показано, что для частот. при которых толщина скинслоя много больше длины свободного пробега, радиус корреляцин совпадает с толщиной скинслоя, а для частот, удовлетворяюших обратному условио - с длиной свободного пробега.

Полученные докладчиками результаты раскрывают фнзический смысл условлй на функцию корреляции сторонних ф.тюктуационных токов і1 полей, феноменологически введенных С. М. Рытовым в теорию тепловых шумов.

В докладс Г. Л. Сучкина (Горький, НИРФИ, - «Обоблцение соотношениї взаимнссти Онзагера на случай линейных спстем, не подчиняющихся теореме взанмности» показано. что нарушение теоремы взаимности Рэлея-Гельмгольца, как это имеет место, например, в ферритовых изоляторах, влечет за собой нарушенне пзвествых в термодннамике необратимых процессов соотношений взаимности Онзагера -- Казимира. Последнес обстоятельство позволяет сформулировать обобшсние волноводноro зақона Кнрхгофda. внервые полученного C. M. Рытовым дая неравновесных невзаимных систем. подчиныюшихся термодинамике необрагимых лроцессов в сле,јуюней форме: пнтенсивность собствснного тенIового э.Тектромагнитного пзлучення полуирозрачного симметричного пзлучателя, не подчнняюшегося теореме взанмности ни в симметричной, ни в антиснмметрнчної форме, опредетяется погтопенпем в направленин излучения,
Ф. В. Бункин (Москва, ФИАН) рассмотрел Эффект Баркгаузена 13 неременном поле».

Секция Eис:ространения волн в ста- . . ководители Н. Г. Денисов (Горький, НИРФИ и В. И. Татарский (Москва, $\mathrm{AH}$ CCCP).

В обзорном докладе $H$. Г. Денисова и В. А. Зверева (Горький, НИРФИ)

распространение волн в средах с случайными неоднородностями» рассматривались феноменологические теории распространения в средах с регулярными неоднородностями и методы вычисления корреляционных функций поля, прошедшего через неоднородный слой, а также методы решения задач дифракции на случайных экранах н обсуждались некоторые вопросы теории рассеяния.

- ооклад Н. Г. Јенисова «O распространении воли в плоско-слоистой среде, содержашей статистические неоднродности» содержал результаты решения соответствуіошей задачи при налични регулярного пзменения показателя преломления по высоте.

11. И. Родак (Москва, ИРЭАН) в док.таде $\approx \mathrm{O}$ рассеянни немонохроматического излучения на блужлаюших неоднородностях» показала, что при рассеянии немонохроматпческого излучения на блюждаюцих неоднородностях функцин коррелящи определяются взвешенной сүммой функцнй корреляции, получающихся при монохроматическом облучени: последнее справедливо и для спектпа pacceянног пзлучения. Получена фуниня коррелянии интенсивності рассеянного поля .лля больших рассеивающих об́ъемов и ряд дрүгих интересных резу.Tь:атов

B токтаде Ю. К. Қалинина (Москва, HИЗ МИР « $\mathrm{K}$ вонросу о pacnpoctpaнeнин «земной волнц» над статистически неоднородной поверхностью» рассматрнвается случай, когда комплексная днэтектрпческая проницаемость является случайной функцией двух переменных для различных трасс.

В кратком сообшении $M$. А. Қалтистратовой изложены результаты экспернментального исследования расселния звуковых волн в приземном слое атмосферы. В докладе О. И. Яковлева и В. Н. Бочарова (Томск, ФТИ) «Об обратиом рассеянин коротких радиоволлі иижней ионосферой» сообшались интересныс результаты теоретического и экспериментального исследования обратного рассеяния радиоволн на нерегулярHbx неоднородностях ионосферы.

В. И. Татарский (Москва, АН СССР) выступил с сообцением на тему: «Рассеянис витн на случайных неоднородностях показателя преломления в приближении френелевской дифракции».

Секция «Статистические явления в коантовы. уси.ителяx, генераторах : cпектроскопах) (руководители секцин: проф. Л. Л. Мясников, доц. В. С. Тро- 
ицкий). Наиболее полно в докладах, заслушанных на секции, были представлены вопросы использования и исследования усилительных и генераторных квантово-механических систем.

Анализу предельной точности нзмерения эффективной темлературы шумов на входе радиометра при выполнении условия $h \omega \approx k T$ был посвящен доклад Н. В. Қарлова и Б. М. Чихачева (Москва, ФИАН) «О чувствительности радиометров в квантовой области». Докладчиками найдена оптимальная температура входных шумов, при которой чувствительность радиометра максимальна. Полученные результаты использованы для вычисления чувствительности радиометра по температуре антенны и рассмотрен вопрос о чувствительности радиотеляскопа при измерении эффективной температуры космических источников радиоизлучения. Показано, что чувствительность радиотелескопов сушественно определяется квантовыми эффектами даже в не квантовой области при $h \omega<k T$.

Теория квантовых усилителей, работающих на пучке молекул аммиака, изложена в докладе В. С. Троицкого и В. Б. Цареградского (Горький, НИРФИ) - «О чувствительности усилителя на пучке возбужденных молекул», показано что надлежащим выбором параметров усилителя можно изменять влияние теплового шума контура на его чувствительность, однако в этом случае возрастают шумы спонтанного излучения молекул. При оптимальных параметрах и комнатной температуре внутренние шумы такого усилителя составляют всего лишь около $8^{\circ}$ по-Кельвину.

В докладе «Влияние спонтанного излучения на спектральную ширину линии молекулярного генератора» В. С Троицким (Горький, НИРФИ) рассмотрен вопрос о влиянии самопроизвольного излучения возбужденных молекул в контуре генератора. Показано, что спонтанное излучение молекул в существующих генераторах приводит к уширению спектральной линин.

При некоторых предположениях о характере спонтанных радиошумов уширение линии равно ширине спектра спонтанного излучения одной молекулы, излучающей в контуре.

В доклапе Сучкина Г. Л. (Горький, НИРФИ) «Возбуждение резонаторов дипольно-излучающими молекулами» в приближении заданных дипольных токов исследован процесс возбуждения резонаторов молекулярных генераторов II усилителей. Найдены предельные значения величины резонаторов, обеспечи вающие исключение влияния продольного Допплер-эффекта. Дана оценка релятивистских эффектов, возникающих за счет собственного движения молекул. Показано, что в случае почти монокинетического пучка продольный Допплерэффект в резонаторе приводит $k$ удвосиюю линич излучения.
Обзорный доклад В. M. Файна (Горький, НИРФИ) «Квантовыс явления в радиодиапазоне» содержал изложение суцественных пля теории квантовых систем в радиодиапазоне результатов голученных докладчиком.

Доклад А. С. Тагера (Москва) II В. М. Файна «Спонтанное излучение системы частиц, размеры которой сравнимы с длиной волны» был посвящен весьма актуальной проблеме спонтанного излучения.

В докладе Ф. В. Бункина (Москва, ФИАН) «Об инверсии уровней зеемановского расщепления» рассматриваетсл влияние поперечных возмушений магнитного поля.

В докладе В. Ф. Волкова, Л. Л. Мясникова, А. И. Наумова и В. В. Строганова (Горький, НИРФИ) — «К методике атомно-лучевой радиоспектроскопии» даются расчеты атомно-лучевого радиоспектроскопа, использующего магнитный резонанс на атомах цезия.

В докладе И. Л. Берштейна І Ю. А. Дрягина (Горький, НИРФИ) «Применение молекулярного генератора в качестве опорного сигнала стабильной частоты для системы фазовой автоподстройки частоты мощного генератора» описывается экспериментальная установка, которая работает так, что восьмая гармоника колебания клистрона с точностью до фазы совпадает с колебанием молекулярного генератора. Относительная стабильность частоты выходного сигнала в этом случае равна относительной стабильности молекулярного генератора.

Следует отметить доклады: С. А. Ахманова, С. Д. Гвоздовера, Ю. С. Kor:стантинова и И. Т. Трофименко (Москва, МГУ) - «Автодинный радиоспектроскоп в 3-сантиметровом диапазоне»; Н. M. Александрова, П. M. Бородина, В. В. Москалева и Ф. И. Скрипова (Ленинград, ЛГУ) — «Разработка аппаратуры для исследования молекулярных и кристаллических структур методом ядерного магнитного резонанса» и Ф. И. Скрипова (Ленинград, ЛГУ) «ядерно-резонансный генератор низкой частоты».

На заключительном пленарном засегании 18 октября участники конференции заслушали обзорный доклад А. Н. Малахова «Фликкер-шум в современных лампах, полупроводниках и других элементаху и доклад А. M. Маненкова (Москва, ФИАН) на тему: «Молекулярнше усилители и генераторы».

В решенин, принятом конференцией, отмечается: «В основном дальнейший прогресс всех без исключения отраслей радиотехники завнсит от разрешения проблем статистической радиофизики, связанных с работой радиоустройств при наличин шуумов јI флюктуаций в при налебательных, радиоизмерительных системах, а также вопросов распространения волн в статистически неоднородных средах. Большую актуальность 
имеют также исследования статистических явлений и шумов в радиоспектроcкопах It квантовых генераторах и усилителях».

Конференция отметила известное отставание этих исследований, в особенности экспериментальных, от запросов практики и вынесла ряд предтожений.

ГІоступила в редакцию

10 XI 1958 r. касающихся научной тематики и организации научной работы.

Конференция обратилась в Министерство высшего образования н Радиоcoset AH CCCP с предложением созвать в 1960-1961 гг. Международную конференцию по статистической радиофизике в г. Москве.

\section{Г. Л. Сучкин}

ت̈аучно-исследовательский радиофизический институт при Горьковском госу-арственном университете нษ. Н. И. Лобачевского 